\title{
Prevalence of intestinal parasitic infection and its association with anemia among pregnant women in Wondo Genet district, Southern Ethiopia: a cross-sectional study
}

Amelo Bolka ${ }^{1}$ and Samson Gebremedhin ${ }^{2^{*}}$ (D)

\begin{abstract}
Background: Previous studies reported contradicting findings about the association between intestinal parasitosis and maternal anemia. In this study we aimed to determine the prevalence of intestinal parasitic infection and its association with anemia among pregnant women in Wondo Genet district, Southern Ethiopia.

Methods: This facility-based cross-sectional study was conducted in June and July 2018. Pregnant women $(n=352)$ were randomly drawn from five health centers using antenatal care follow-up lists. Trained data collectors administered the questionnaire. Capillary blood was collected and analyzed for hemoglobin using the HemoCue method. Stool sample was collected following standard procedure and analyzed for the presence and types of intestinal parasites using direct microscopy with Formalin-ether concentration technique. Association between intestinal parasitosis and anemia was measured using multivariable binary logistic regression analysis. The outputs are presented using adjusted odds ratio (AOR) with 95\% confidence intervals (Cl).

Results: The overall prevalence of intestinal parasitic infection was 38.7\% (95\% Cl: 33.6-43.8\%). One-tenth (9.7\%) of the pregnant women were infected with polyparasites. Ascaris lumbricoides was the predominant infection encountered in 24.9\% of the women. The other infections identified were: hookworms (11.2\%), Giardia lamblia (5.4\%), Entamoeba histolytica (3.4\%), Trichuris trichiura (2.9\%) and Schistosoma mansoni (2.3\%). The mean ( \pm standard deviation) hemoglobin concentration was $12.3( \pm 1.9) \mathrm{g} / \mathrm{dl}$ and 31.5\% (95\% Cl: 26.6-36.4\%) women were anemic (hemoglobin $<11 \mathrm{~g} / \mathrm{dl}$ ). The prevalence of anemia among women infected with intestinal parasite (55.6\%) was substantially higher than the prevalence in their counterparts $(16.4 \%)(p<0.001)$. In a multivariable model adjusted for multiple potential confounders including socio-economic status indicators, the odds of anemia were six times increased (AOR $=6.14,95 \% \mathrm{Cl}: 2.04-18.45)$ among those affected by at least one intestinal parasite.
\end{abstract}

Conclusion: Strengthening the existing water, sanitation and hygiene programs and routine deworming of pregnant mothers may help to reduce the burden of both intestinal parasitic infection and anemia in pregnant women.

Keywords: Intestinal parasitic infection, Intestinal helminths, Anemia, Pregnancy, Hemoglobin, Ethiopia

\footnotetext{
*Correspondence: samsongmgs@yahoo.com

2Department of Public Health, St Paul's Hospital Millennium Medical College,

Addis Ababa, Ethiopia

Full list of author information is available at the end of the article
}

(c) The Author(s). 2019 Open Access This article is distributed under the terms of the Creative Commons Attribution 4.0 International License (http://creativecommons.org/licenses/by/4.0/), which permits unrestricted use, distribution, and reproduction in any medium, provided you give appropriate credit to the original author(s) and the source, provide a link to the Creative Commons license, and indicate if changes were made. The Creative Commons Public Domain Dedication waiver (http://creativecommons.org/publicdomain/zero/1.0/) applies to the data made available in this article, unless otherwise stated. 


\section{Background}

Between 1990 and 2010, the global prevalence of anemia declined by nearly $20 \%$ from 40 to $33 \%$ [1]. Yet, anemia remains a major concern with moderate or severe public health significance in more than $80 \%$ of the world countries [2]. In 2010 anemia affected more than two billion people globally and contributed to $9 \%$ of total years of life lived with disability [1]. Children under five years of age, pregnant women and women of reproductive age bear the highest burden [1, 2]. Anemia prevalence exceeds $50 \%$ in many regions of the subSaharan Africa [1]. According to the 2005 estimate, anemia has severe public health significance in Ethiopia [2]. In 2016, the national prevalence among pregnant women was $29 \%$ and the figure did not decline over the previous decade $[3,4]$.

Anemia has multifaceted and frequently coexisting etiologies. Iron deficiency is regarded as the primary cause contributing to nearly $50 \%$ of the global burden of anemia $[1,2]$. Parasitic infections including malaria, hookworms and schistosomiasis may explain nearly a quarter of anemia [1]. Further hemoglobinopathies, acute or chronic infections and other nutritional deficiencies have ethological significances [1, 2]. During pregnancy, hemodilution - disproportionate increase in plasma volume as compared with red cell mass - is a key cause of prenatal hemoglobin decline. Contextual factors including poverty and limited access to health care are also important root causes [1].

Maternal anemia leads to multiple and serious consequences. Observational studies suggested that anemia in pregnancy increases the risks of maternal mortality and low birthweight [5]. A systematic review confirmed that $1 \mathrm{~g} / \mathrm{dl}$ increase in mean hemoglobin level in late pregnancy is associated with nearly $30 \%$ reduction in the odds of maternal mortality [6]. Further prenatal iron supplementation during pregnancy increases birthweight and reduces risk of prematurity [7-9]. Anemia in pregnancy may also increase risks of premature birth and perinatal mortality [10].

According to the World Health Organization (WHO), about one-fourth of the world population is infected with intestinal parasites primarily Ascaris lumbricoides, Trichuris trichiura and hookworms [11]. Intestinal parasites may cause or aggravate anemia via multiple and interactive mechanisms [12, 13]. Hook worms,schistosomiasis and, Trichuris trichiura lead to intestinal blood loss. Many intestinal parasites reduce appetite and compromise nutrient intake. Further helminthiasis-inducted intestinal inflammation may limit absorption of nutrients. Intestinal parasites may promote indigenous nutrient loss by inducing intestinal mucosa damage, impairing digestion and causing diarrhea. Giardia lamblia and Entamoeba histolytica also cause blood loss and inflammation-induced restriction of iron absorption $[12,13]$.

The association between intestinal parasitosis and anemia among children is well established and systematic reviews suggested deworming after a confirmed infection results in a significant hemoglobin rise in children $[5,13]$. However, the significance of parasitic infection to anemia in pregnancy has not been thoroughly explored and the existing evidence is equivocal. Observational studies conducted in Hadiya district, Southern Ethiopia [14], Western Ethiopia [15], Nigeria [16], Venezuela [17] and Philippines [18] reported positive associations. Conversely, a study conducted in Papua New Guinea found no significant relationship [19]. Further, according to a systematic review, a single dose of antihelminthic in the second trimester of pregnancy showed no effect on the hemoglobin status of pregnant women [20].

In this cross-sectional study we aimed to determine the prevalence of intestinal parasitic infection and its relationship with anemia among pregnant women in Wondo Genet district, Southern Ethiopia.

\section{Methods \\ Study design}

This facility-based cross-sectional study was conducted in June and July 2018 among pregnant women booked for antenatal care (ANC) in five public health centers of Wondo Genet district, Southern Ethiopia.

\section{Study setting}

Wondo Genet is situated in Sidama zone, Southern Ethiopia and has an estimated population size of 163 , 000. Administratively it is classified into 13 rural and 2 urban villages. The altitude of the district ranges from 1761 to $2695 \mathrm{~m}$ above sea level (ASL) and the area is characterized by two distinct agro-ecological zones. Midlands, land mass ranging between 1750 to $2300 \mathrm{~m} \mathrm{ASL}$, contribute for $62 \%$ of the population; whereas, highlands (above $2300 \mathrm{~m} \mathrm{ASL}$ ), contribute for the remaining 38\% the population. The average rainfall is $1120 \mathrm{~mm}$ per annum and according to the season, temperatures vary from 7 to $26^{\circ} \mathrm{C}$. The main rainy season is between July and early October. About $85 \%$ of the population livelihood depends on subsistent farming. The district has 5 health centers and 16 functional health posts.

In Ethiopia the constellation of services provided within the ANC package include, but not limited to, iron folic acid supplementation, deworming, HIV testing, nutrition counseling and intermittent preventive treatment for malaria.

\section{Sample size determination and sampling approach}

Sample size adequate for estimating prevalence of anemia and intestinal parasitosis was determined 
independently using single population proportion formula. The specifications made in the computation were: $95 \%$ confidence level, 5\% margin of error, $32.8 \%$ expected prevalence of anemia [21], 29.5\% expected prevalence of intestinal parasitosis [22] and 10\% compensation for possible non-response. Ultimately sample size of 352 was judged to be sufficient.

Similarly, the adequacy of the sample size for determining the association between intestinal parasitosis and anemia status was evaluated using double population proportion formula using Epi InfoTM 7 statistical package with the inputs of: $95 \%$ confidence level, $80 \%$ power, 1:3 ratio between subjects with and without intestinal parasitosis and odds ratio (OR) of 2.4 [23].

Study participants were selected from the five health centers using stratified sampling approach (i.e. considering each health facility as stratum). During the survey 1739 women were booked for ANC and were eligible for the study. Initially, the total sample size was allocated to the facilities proportional to their ANC clients flow rate. Ultimately the individual women were selected using systematic random sampling technique with sampling interval of five.

\section{Data collection}

Data were collected using pretested, structured and interviewer administered questionnaire by seven trained nurses and public health officers. Socio-demographic related questions were directly extracted from the standard Demographic and Health Survey (DHS) questionnaire [3]. Gestational age was determined based on women's recall of last normal menstrual period. Knowledge of the mothers on anemia was assessed using a set of questions developed by the investigators. Dietary diversity of the women was assessed using the Women's Dietary Diversity Score questionnaire of the Food and Agriculture Organization of the United Nations (FAO). The respondents were asked whether they ate from nine standard food groups in the previous day of the survey without setting minimum intake restrictions. Ultimately dietary diversity score (DDS) was computed out of maximum score of nine and categorized into low $(<4)$, medium (4-5) or high (>5) [24]. Mid-upper arm circumference (MUAC) and height was measured following standard procedures. Pregnant women with MUAC less than 21 $\mathrm{cm}$ were considered as malnourished [25].

Stool samples collected as part of the routine ANC are used for the study. Stool samples were collected from the women using clean screw-top containers and within an hour of collection stool microscopy was made at the respective health centers by five Bachelor's degree holder laboratory technicians. Direct microscopy with Formalin-ether concentration technique was employed to identify the parasites [26]. In order to reduce inter- observer variation, stool samples were independently examined by two technicians.

Hemoglobin concentration was determined from a random finger-tip capillary blood using HemoCue 301. Hemoglobin measurements were adjusted for altitude according to the recommendation of the WHO [27] and, classified as normal $(>11.0 \mathrm{~g} / \mathrm{dl})$ or mild $(10.0-10.9 \mathrm{~g} / \mathrm{dl})$, moderate $(7.0-9.9 \mathrm{~g} / \mathrm{dl})$ and severe $(<7.0 \mathrm{~g} . \mathrm{dl})$ anemia.

This manuscript is organized according to the STrengthening the Reporting of OBservational studies in Epidemiology (STROBE) guideline and the STROBE checklist is provided as a supporting file (Additional file 1).

\section{Data management and analysis}

Collected data were checked for completeness and consistency and entered into SPSS version 20 statistical package for analysis. Data were described using frequency distributions, tables and measures of central tendency and dispersion. The association between specific type of intestinal parasites and anemia was presented using chi-square or fisher exact test. Further, the relationship between intestinal parasitosis and anemia was determined using bivariable and multivariable binary logistic regression analyses and the outputs are presented using crude (COR) and adjusted (AOR) odds ratio. Independent variables having $p$-value of 0.2 or less in the bivariable models were considered as potential confounders, and hence adjusted in the multivariable model. The thirteen variables that were adjusted in the multivariable model were age, educational status, place of residence, monthly income, family size, birth interval, parity, history of deworming in the last 6 months, iron supplementation during the pregnancy, feeding pattern during pregnancy (as usual or more than usual), receiving nutritional counseling during pregnancy, MUAC and toilet ownership. In the multivariable model multicollinearity among independent variables was assessed using Variance Inflation Factor and found to be within acceptable limits $(<10)$. The model goodness-of-fit was evaluated using the Hosmer-Lemeshow statistic.

\section{Ethical consideration}

Ethical clearance was obtained from Institutional Review Board of College of Medicine and Health Science, Hawassa University. Data were collected after taking informed verbal consent from each of the study participants. As all the study subjects were 18 years or above, consent was directly taken from them. Verbal consent, rather than written consent, was preferred because onethird of the study subjects did not have formal education. The same was approved by the institutional review board. Pregnant mothers found to have anemia and/or intestinal parasites were linked with clinicians at the health centers and received treatment. 


\section{Results}

\section{Characteristics of the respondents}

A total of 349 pregnant women following ANC took part in the study making the response rate $99.1 \%$. The participants were selected from five health centers located at altitude ranging from 1761 to $2690 \mathrm{~m}$ ASL. Nearly three-fourths $(72.2 \%)$ of the study participants were drawn from the midland kebeles. The majority of the women $(72.2 \%)$ were rural dwellers.

The mean $( \pm$ SD) age of the women was $25.7( \pm 4.7)$ years and the vast majority $(87.1 \%)$ were within the age bracket of 20 to 35 years. The majority of women worked as housewives (80.2\%), were from the Sidama ethnic group $(72.8 \%)$, were predominantly Protestant (85.4\%) and nearly 1 in $3(29.2 \%)$ were illiterate. The median monthly income was 2500 Ethiopian birr (equivalence of 90 USD) and ranged from 600 to 5995 birr. The average $( \pm \mathrm{SD})$ household size was $4.8( \pm 1.8)$ (Table 1$)$.

During the study the mean gestational age of the women was $26.6( \pm 5.5)$ weeks. Near to two-thirds $(63.3 \%)$ were in their third trimester and the remaining (36.7\%) were in the second trimester. The median parity was 2 and ranged from 0 to 8 . About 18.6 and $11.7 \%$ of the study participants were nulliparas and grand multiparas, respectively. Among those who had at least two births before, $45.0 \%$ had short (less than 2 years) birth interval.

Three fourth $(78.5 \%)$ of the respondents use piped water as their usual source of drinking water; while remaining 14.6 and $6.9 \%$ use protected and unprotected well/spring, respectively. Majority $(81.4 \%)$ of the women reported that they somehow treat water before consumption. The approaches used for treating water include: adding disinfectants $(74.3 \%)$, strain through cloth (16.9\%), use of water filter (6.7\%) and boiling $(2.1 \%)$. About three-fourths (71.3\%) owned a toilet facility.

\section{Knowledge of pregnant women on anemia}

Out of the 349 respondents, $76.8 \%$ reported they had ever heard of anemia before. Among those who were aware of anemia, 83.9, 96.3 and 48.1\% knew anemia during pregnancy can be caused by bleeding, undernutrition and infections, respectively. Out of total respondents, $72.8 \%$ were aware of at least one possible consequence of anemia in pregnancy. The most frequently mentioned consequences were: perinatal mortality $(92.5 \%)$, maternal mortality (82.3\%), low birthweight (66.1\%) and neonatal morbidity and mortality (55.5\%). Three-fourths of the respondents (74.5\%) knew anemia is a preventable condition. The most commonly cited preventive measures were: eating diversified diet (97.7\%), taking iron and folic acid tablets during pregnancy (94.6\%), birth spacing (88.5\%), preventing infection
Table 1 Socio-demographic and economic characteristics among pregnant women attending antenatal care in health centers of Wondo Genet district, Southern Ethiopia, 2018

\begin{tabular}{|c|c|c|}
\hline Variables $(n=349)$ & Frequency & Percent \\
\hline \multicolumn{3}{|l|}{ Age (years) } \\
\hline $18-20$ & 36 & 10.3 \\
\hline $20-35$ & 304 & 87.1 \\
\hline$>35$ & 9 & 2.6 \\
\hline \multicolumn{3}{|l|}{ Ethnic group } \\
\hline Sidama & 254 & 72.8 \\
\hline Oromo & 54 & 15.5 \\
\hline Amhara & 19 & 5.4 \\
\hline Others & 22 & 6.3 \\
\hline \multicolumn{3}{|l|}{ Religion } \\
\hline Protestant & 298 & 85.4 \\
\hline Muslim & 33 & 9.5 \\
\hline Orthodox & 18 & 5.2 \\
\hline \multicolumn{3}{|l|}{ Place of residence } \\
\hline Rural & 252 & 72.2 \\
\hline Urban & 97 & 27.8 \\
\hline \multicolumn{3}{|l|}{ Educational status $(n=347)$} \\
\hline Illiterate & 102 & 29.2 \\
\hline Informal education & 35 & 10.0 \\
\hline Primary level & 147 & 42.7 \\
\hline Secondary level or above & 63 & 18.1 \\
\hline \multicolumn{3}{|l|}{ Education level of the husbands } \\
\hline Illiterate & 72 & 20.6 \\
\hline Informal education & 51 & 14.6 \\
\hline Primary level & 115 & 33.0 \\
\hline Secondary level and above & 111 & 31.8 \\
\hline \multicolumn{3}{|l|}{ Occupation of the respondent } \\
\hline Housewife & 280 & 80.2 \\
\hline Merchant & 39 & 11.2 \\
\hline Government employee & 25 & 7.2 \\
\hline Daily laborer & 5 & 1.4 \\
\hline \multicolumn{3}{|l|}{ Occupation (husband) } \\
\hline Farmer & 176 & 50.4 \\
\hline Merchant & 105 & 30.1 \\
\hline Government employee & 48 & 13.8 \\
\hline Daily laborer & 20 & 5.7 \\
\hline \multicolumn{3}{|c|}{ Monthly income of the household (ETB) } \\
\hline$<2480$ Eth birr & 166 & 47.6 \\
\hline$>=2480$ Eth birr & 183 & 52.4 \\
\hline \multicolumn{3}{|l|}{ Household size } \\
\hline 1-4 member & 178 & 51.0 \\
\hline$>=5$ member & 171 & 49.0 \\
\hline
\end{tabular}


including intestinal parasites (47.7\%) and specifically taking deworming medications (43.0\%).

\section{Dietary diversity and nutritional status of pregnant women}

The overall quality of diet of the pregnant women was also assessed based on the diet consumed in the preceding day. Cereals (99.1\%), vitamin A rich fruits and vegetables $(88.3 \%)$, roots and tubers $(86.2 \%)$ and foods made of oil, fat or butter $(83.1 \%)$ were consumed by the vast majority of the subjects. Legumes (69.6\%) and milk or milk products $(55.3 \%)$ were also taken by more than half of them. Food groups that were less frequently consumed were: other fruits (37.0\%), other vegetables (23.5\%), eggs (18.1\%), flesh foods (12.6\%) and fish (0.0\%).

The mean $( \pm$ SD) DDS was 4.0 ( \pm 1.6$)$. Only $19.5 \%$ consumed from 6 or more groups indicative of high dietary diversity. Conversely, $38.4 \%$ had medium (4-5 food groups) and $42.1 \%$ had low DDS (less than 4 food groups).

The mean MUAC of the respondents' was $22.8( \pm 1.9)$ $\mathrm{cm}$. About one-fifth $(20.6 \%)$ of the pregnant women had MUAC less than $21 \mathrm{~cm}$ suggestive of acute malnutrition. Smaller proportions (1.1\%) of the pregnant women had short stature (height less than $145 \mathrm{~cm}$ ).

Fifty five percent of the pregnant women took deworming medication at least once in the preceding 6 months of the survey. Similarly, $45.3 \%$ reported that they took iron supplement during the current pregnancy.

\section{Prevalence of intestine parasitosis and anemia}

The overall prevalence of intestinal parasite infection was $38.7 \%$ (95\% CI: 33.6-43.8\%). One-tenth (9.7\%) were infected with polyparasites. A. lumbricoides was the most common infection (24.9\%) followed by hookworms (11.2\%), G. lamblia (5.4\%), E. histolytica (3.4\%), T. trichiura (2.9\%) and S. mansoni (2.3\%).

The mean hemoglobin concentration was $12.3( \pm 1.9)$ $\mathrm{g} / \mathrm{dl}$ and ranged from 7.1 to $18.2 \mathrm{~g} / \mathrm{dl}$. It was found that 31.5\% (95\% CI: 26.6-36.4\%) pregnant women were anemic. The prevalence of mild and moderate anemia were 21.5 and $10.0 \%$, respectively. None of the women had severe anemia.

\section{Association between intestinal parasitosis and anemia}

The prevalence of anemia among pregnant women infected with intestinal parasite $(55.6 \%)$ was significantly higher than the prevalence among women who were not infected $(16.4 \%)(p<0.001)$. Nearly all of the mothers infected with hookworm (92.3\%) were anemic. Further the prevalence of anemia was alarmingly high among mothers diagnosed with other parasites: $G$ lamblia (78.9\%), S mansoni (75.0\%), E histolytica (50.0\%), T trichiura (50.0\%) and A lumbricoides $40.2 \%$. Statistically significant association was observed between anemia and hookworm, G. lamblia, S. mansoni and A. lumbricoides infections $(p<0.05)$ (Table 2).

The bivariable logistic regression analysis suggested women who were infected with intestinal parasites had 6 times increased odds of anemia $(\mathrm{COR}=6.39,95 \% \mathrm{CI}$ : $3.89-10.50)$ as compared to their counterparts. In the multivariable model in which 13 potential confounders were adjusted, the odds of anemia were also six times increased (AOR $=6.14,2.04-18.45)$ among individuals infected with intestinal parasites (Table 3). The outputs of the full regression model is now provided as a supporting file (Additional file 2).

\section{Discussion}

The study suggested that more than one-third (38.7\%) of pregnant women in Wondo Genert have intestinal parasitic infections and co-infection with polyparasites was common. Further, 31.5\% have low hemoglobin level indicative of anemia. After adjusting for potential

Table 2 Association between specific types of intestinal parasitosis and anemia among pregnant women from Wondo Genet district, Southern Ethiopia, 2018

\begin{tabular}{|c|c|c|c|c|}
\hline \multirow{2}{*}{$\begin{array}{l}\text { Type of } \\
\text { helminth } \\
\text { infection }\end{array}$} & \multicolumn{2}{|c|}{ Anemia } & \multirow{2}{*}{$\begin{array}{l}\text { Prevalence } \\
\text { of anemia } \\
(\%)\end{array}$} & \multirow{2}{*}{$\begin{array}{l}\text { Statistical } \\
\text { test } \\
(p \text {-value })^{\times}\end{array}$} \\
\hline & Yes & No & & \\
\hline \multicolumn{5}{|c|}{ Any helminth infection } \\
\hline Yes & 75 & 60 & 55.6 & \multirow[t]{2}{*}{$<0.001^{*}$} \\
\hline No & 35 & 179 & 16.4 & \\
\hline \multicolumn{5}{|c|}{ Hookworm } \\
\hline Yes & 36 & 3 & 92.3 & \multirow[t]{2}{*}{$<0.001^{*}$} \\
\hline No & 74 & 236 & 23.9 & \\
\hline \multicolumn{5}{|c|}{ Giardia lamblia } \\
\hline Yes & 15 & 4 & 78.9 & \multirow[t]{2}{*}{$<0.001^{*}$} \\
\hline No & 95 & 235 & 28.8 & \\
\hline \multicolumn{5}{|c|}{ Schistosoma mansoni } \\
\hline Yes & 6 & 2 & 75.0 & \multirow[t]{2}{*}{$0.007^{*}$} \\
\hline No & 104 & 237 & 30.5 & \\
\hline \multicolumn{5}{|c|}{ Ascaris lumbricoides } \\
\hline Yes & 35 & 52 & 40.2 & \multirow[t]{2}{*}{$0.043^{*}$} \\
\hline No & 75 & 187 & 28.6 & \\
\hline \multicolumn{5}{|c|}{ Entamoeba histolytica } \\
\hline Yes & 6 & 6 & 50.0 & \multirow[t]{2}{*}{0.205} \\
\hline No & 104 & 233 & 30.9 & \\
\hline \multicolumn{5}{|c|}{ Trichuris trichiura } \\
\hline Yes & 5 & 5 & 50.0 & \multirow[t]{2}{*}{0.298} \\
\hline No & 105 & 234 & 31.0 & \\
\hline
\end{tabular}

$\times$ Chi-square test for the first 5 variables and fisher exact test for the last 2 variables

* Statistically significant difference at $p$-value of 0.05 
Table 3 Association between intestinal parasitosis and anemia among pregnant women from Wondo Genet district, Southern Ethiopia, 2018

\begin{tabular}{lllll}
\hline $\begin{array}{l}\text { Intestinal } \\
\text { parasitosis } \\
(n=349)\end{array}$ & \multicolumn{2}{l}{ Anemia } & COR & AOR $^{a}$ \\
\cline { 2 - 3 } & Yes & No & & \\
\hline Yes & 75 & 60 & $6.39(3.89-10.50)^{*}$ & $6.14(2.04-18.45)^{*}$ \\
No & 35 & 179 & 1 & 1 \\
\hline
\end{tabular}

${ }^{a}$ Adjusted for age, educational status, place of residence, family size, monthly income, birth interval, parity, history of deworming in the last 6 months, iron supplementation during the pregnancy, feeding pattern during pregnancy (as usual or more than usual), receiving nutritional counseling during pregnancy, MUAC and toilet ownership

*Statistical significant assocatin at $p$-value of 0.05

confounders, we observed a strong positive association between intestinal parasitic infection and anemia.

The prevalence of anemia reported in this study is within the 20 to $40 \%$ range indicative of moderate public health significance of anemia in a population [2]. Multiple community- or facility-based surveys in Ethiopia concluded the same [3, 28-31]. The recent DHS found $24 \%$ of women of reproductive age and $29 \%$ of pregnant women in Ethiopia are anemic [3]. Facility-based surveys in Butajira general hospital, Southern Ethiopia (27.6\%) [28]; Bisdimo district hospital, Southeast Ethiopia (27.9\%) [29]; Nekemte Referral hospital, Western Ethiopia (29\%) [30]; and Arba Minch town health institutions, Southern Ethiopia (32.8\%) [31], also reported comparable prevalence figures.

In this study the overall magnitude of the intestinal parasitic infection was $39 \%$, with the highest prevalence for A. lumbricoides (25\%) and hookworms (11\%). Other studies in Ethiopia reported assorted magnitudes and patterns, suggesting the existence of substantial variation in the epidemiology of intestinal parasites in the country [15, 22, 31-33]. A study in Mecha district, Northwest Ethiopia reported an exceptionally high prevalence (70\%) and identified A. lumbricoides (33\%), S. mansoni (17\%) and Hookworms (14\%) as the predominant infections [32]. A study among pregnant women following ANC in a referral hospital in Northwest Ethiopia reported a comparable figure to our finding (32\%) yet the major infections were protozoan: G. lamblia (13\%) and E. histolytica (8\%) [33]. A similar study conducted in a district hospital in Hossana town, reported $30 \%$ total prevalence and A. lumbricoides was the commonest infection affecting $10 \%$ of the women [22]. A study in West Gojam zone estimated 37\% aggregate prevalence and, hookworm was most frequently encountered parasite (19\%) [34]. A study in Western Ethiopia based on data from multiple health centers found $25 \%$ prevalence of parasitosis with the predominance of Hookworms (15\%) followed by $A$. lumbricoides (7\%) [15].
After controlling for potential confounders including multiple socioeconomic status indicators, we observed a statistically significant and strong association (AOR = 6.14) between intestinal parasitosis and anemia. In Ethiopia, a couple of studies conducted in Eastern Wollega $(\mathrm{AOR}=1.8)$ and Gilgil Gibe Dam area $(\mathrm{AOR}=1.8)$ reported significant but weaker associations [15, 35]. The differences observed in the strength of association can possibly be due to variation in intensity of parasitic infections or other contextual factors not studied in the study. As described earlier, the observed association could be explained by several biological mechanisms. Intestinal parasites may impair iron status by sucking blood from intestinal wall or by facilitating chronic blood loss, reducing appetite and nutrient intake, competing for iron and causing diarrhea/dysentery $[12,13]$.

This finding may imply that, on top of the routine prenatal iron supplementation, preventive or therapeutic deworming integrated with ANC may help to reduce the burden of maternal anemia. From public health perspectives this would give more sense in consideration of the fact that merely half of the pregnant women in our study received deworming medications in the preceding 6 months. According to the national guideline of Ethiopia, pregnant women should be routinely dewormed in the second or third trimester of pregnancy. Yet, a national survey indicated that in 2016 only $6 \%$ of the pregnant women received deworming medication [3].

The strength of the study is the fact that it enrolled relatively large number of pregnant women $(n=349)$ from multiple health facilities and presented prevalence figures for various intestinal parasites. Further, we attempted to measure and accounted for multiple confounders that can independently explain the association between the variables of interest. Yet, the following shortcomings should be taken into considerations while interpreting our findings. Like many other observational studies, we adjusted for potential confounders using regression model. Yet, residual confounding or confounding from unmeasured confounding (e.g. malaria, HIV, other co-morbidities) cannot be excluded. As nearly half of the study subjects received deworming treatment in the preceding 6 months of the survey, the study is likely to underestimate the underlying magnitude of the problem. Due to the cross-sectional nature of the study we could not be able to capture the seasonal variations in the prevalence of intestinal parasitosis. Previous studies have witnessed that prevalence of many intestinal parasites in human population is subjected to inter-seasonal fluctuation [36, 37]. Further, as the study was limited to pregnant women attending ANC, the findings may not be directly extrapolated to pregnant women devoid of prenatal care. In addition, we did not measure intensity of parasitic infection and accordingly we did not manage 
to explore the does-effect relationship between intestinal parasitosis and anemia. It is also important to note that the study was only limited to intestinal parasitosis and did not look into the effect of malaria - an important hemoparasite in the locality.

\section{Conclusion}

The study indicated that $39 \%$ of the pregnant women in Wondo Genet district have intestinal parasitic infections and $32 \%$ were anemic. The most common types of intestinal parasites were A. lumbricoides and hookworm. Coinfection with multiple parasites was commonly encountered. Further, a strong association was observed between intestinal parasitosis and anemia. Strengthening the existing water, sanitation and hygiene programs and routine deworming of pregnant mothers may help to reduce the burden of anemia.

\section{Additional files}

Additional file 1: STROBE Statement. (DOC $86 \mathrm{~kb}$ )

Additional file 2: Full output of multivariable binary logistic regression analysis. Wondo Genet district, Southern Ethiopia, 2018. (DOCX 20 kb)

\section{Abbreviations \\ ANC: Antenatal Care; AOR: Adjusted Odds Ratio; ASL: Above Sea Level; Cl: Confidence Intervals; COR: Crude Odds Ratio; DHS: Demographic and Health Survey; FAO: Food and Agriculture Organization; MUAC: Mid-upper arm circumference; OR: Odds Ratio; SD: Standard Deviation; WHO: World Health Organization}

\section{Acknowledgements}

We are grateful to the Hawassa University and Wondo Genet District Health Unit for funding the study. We also like to sincerely acknowledge the managers of the health centers, study participants and the data collectors.

\section{Authors' contributions}

$A B$ conceived and designed the study; collected analyzed and interpreted the data; and drafted the manuscript. SG participated in the designing of the study and supervised of the fieldwork and the data analysis. Both the authors critically reviewed the manuscript for intellectual content and approved the final manuscript.

\section{Funding}

The financial support for this study came from Hawassa University and Wonedo Genet Town Health Unit, Ethiopia. Both of the funding bodies did not involve in the collection, analysis, and interpretation of data and in writing of the manuscript.

\section{Availability of data and materials}

The datasets analyzed during the current study are not publicly available due institutional regulation but are available from the corresponding author on reasonable request.

\section{Ethics approval and consent to participate}

Ethical clearance was obtained from the Institutional Review Board of Hawassa University, College of Medicine and Health Sciences. Prior to data collection, verbal informed consent was obtained from the respondents. Verbal consent, rather than written consent, was preferred because significant proportions of subjects did not have formal education. The same was approved by the institutional review board.

\section{Consent for publication}

Not applicable.

\section{Competing interests}

The authors declare no competing interest.

\section{Author details}

${ }^{1}$ Wonedo Genet Town Health Unit, Wondo Genet, Ethiopia. ${ }^{2}$ Department of Public Health, St Paul's Hospital Millennium Medical College, Addis Ababa, Ethiopia.

Received: 1 May 2019 Accepted: 27 May 2019

Published online: 30 May 2019

\section{References}

1. Kassebaum NJ, Jasrasaria R, Naghavi M, Wulf SK, Johns N, Lozano R, et al. A systematic analysis of global anemia burden from 1990 to 2010. Blood. 2014;123(5):615-24.

2. de Benoist B, McLean E, Egli I, Cogswell M, editors. Worldwide prevalence of anaemia, vol. 1993-2005. Geneva: WHO Global Database on Anaemia. World Health Organization; 2008.

3. Central Statistical Agency [Ethiopia], the DHS Program. Ethiopia: Demographic and health survey 2016. CSA and ICF: Addis Ababa and Maryland; 2017.

4. Central Statistical Agency [Ethiopia], the DHS Program. Ethiopia: Demographic and health survey 2005. CSA and ICF: Addis Ababa and Maryland; 2006.

5. Black RE, Victora CG, Walker SP, Bhutta ZA, Christian P, de Onis M, et al. Maternal and child undernutrition and overweight in low-income and middle-income countries. Lancet. 2013;382:427-51.

6. Murray-Kolb LE, Chen L, Chen P, Shapiro M, Caulfield L. CHERG iron report: maternal mortality, child mortality, perinatal mortality, child cognition, and estimates of prevalence of anemia due to iron deficiency. Accessed from: http://cherg.org/publications/iron-report.pdf. Accessed on: 04 Nov 2018.

7. Imdad A, Bhutta ZA. Routine iron/folate supplementation during pregnancy: effect on maternal anaemia and birth outcomes. Paediatr Perinat Epidemiol. 2012;26(S1):168-77.

8. Mwangi MN, Roth JM, Smit MR, Trijsburg L, Mwangi AM, Demir AY. Effect of daily antenatal Iron supplementation on Plasmodium infection in Kenyan women: a randomized clinical trial. JAMA. 2015;314(10):1009-20.

9. Mwangi MN, Prentice AM, Verhoef $\mathrm{H}$. Safety and benefits of antenatal oral iron supplementation in low-income countries: a review. Br J Haematol. 2017;177(6):884-95.

10. Rahman MM, Abe SK, Rahman MS, Kanda M, Narita S, Bilano V, et al. Maternal anemia and risk of adverse birth and health outcomes in low- and middle-income countries: systematic review and meta-analysis. Am J Clin Nutr. 2016;103(2):495-504

11. World Health Organization. Soil-transmitted helminth infections: key facts. 2018. Accessed from: http://www.who.int/news-room/fact-sheets/detail/soiltransmitted-helminth-infections. Accessed on: 04 Nov 2018.

12. Pullan $\mathrm{R}$, Brooker $\mathrm{S}$. The health impact of polyparasitism in humans: are we under-estimating the burden of parasitic diseases? Parasitology. 2008;135(7): 783-94.

13. Stephenson LS, Latham MC, Ottesen EA. Malnutrition and parasitic helminth infections. Parasitology. 2000;121 Suppl:S23-38.

14. Lebso M, Anato A, Loha E. Prevalence of anemia and associated factors among pregnant women in southern Ethiopia: a community based crosssectional study. PLoS One. 2017;12(12):e0188783.

15. Mengist HM, Zewdie A, Belew A. Intestinal helminthic infection and anemia among pregnant women attending ante-natal care (ANC) in east Wollega, Oromia, Ethiopia. BMC Res Notes. 2017;10:440.

16. Philomena NO, Tina CN, Agugo UA, Nkechi MO. The prevalence of intestinal parasites and anaemia among pregnant women attending antenatal clinic in federal medical Centre Owerri, Imo state, Nigeria. Journal of Biology, Agriculture and Healthcare. 2014;4(25):171-7.

17. Rodríguez-Morales AJ, Barbella RA, Case C, Arria M, Ravelo M, Perez H, et al. Intestinal parasitic infections among pregnant women in Venezuela. Infect Dis Obstet Gynecol. 2006;2006:23125.

18. Amado JY, Reyes MY. Association between anemia and intestinal parasitism among pregnant women (ages 15-44 years-old) attending antenatal clinic in a tertiary hospital. PJOG. 2015;39(3):1-6.

19. Phuanukoonnon S, Michael A, Kirarock WS, Pomat WS, van den Biggelaar $\mathrm{AH}$. Intestinal parasitic infections and anaemia among pregnant women in the highlands of Papua New Guinea. PNG Med J. 2013;56(3-4):119-25. 
20. Salam RA, Haider BA, Humayun Q, Bhutta ZA. Effect of administration of antihelminthic for soil-transmitted helminths during pregnancy. Cochrane Database Syst Rev. 2015;(18, 6):CD005547.

21. Bekele A, Tilahu M, Mekuria A. Prevalence of anemia and its associated factors among pregnant women attending antenatal care in health institutions of Arba Minch town, Gamo Gofa zone, Ethiopia. Anemia. 2016; 2016:ID1073192.

22. Tesfaye DJ, Beshir WG, Dejene T, Tewelde T. Prevalence of intestinal helminthiases and associated factors among pregnant women attending antenatal clinic of Nigist Eleni Mohammed memorial hospital, Hossana,Southern Ethiopia. Open Access Library Journal. 2015;2(7):1-11.

23. Gedefaw L, Ayele A, Asres Y, Mossie A. Anemia and associated factors among pregnant women attending antenatal care clinic in Wolayita Sodo town, southern Ethiopia. Ethiop J Health Sci. 2015;25(2):155-162.24.

24. Food and Agriculture Organization of the United Nations (FAO). Guidelines for measuring household and individual dietary diversity. FAO: Rome; 2013.

25. Ververs M, Antierens A, Sackl A, Staderini N, Captier V. Which anthropometric indicators identify a pregnant woman as acutely malnourished and predict adverse birth outcomes in the humanitarian context? PLoS Curr. 2013;5. https://doi.org/10.1371/currents.dis. 54a8b618c1bc031ea140e3f2934599c8.

26. Cheesbrough M. District laboratory practice in tropical countries Cambridge: Cambridge University Press; 2006.

27. World Health Organization. Hemoglobin concentrations for the diagnosis of anemia and assessment of severity. Accessed from: http:/www.who.int/ vmnis/indicators/haemoglobin/en/. Accessed on: 04 Nov 2018.

28. Getahun W, Belachew T, Wolide AD. Burden and associated factors of anemia among pregnant women attending antenatal care in southern Ethiopia. BMC Res Notes. 2017;10:276.

29. Kefiyalew F, Zemene E, Asres Y, Gedsefaw L. Anemia among pregnant women in Southeast Ethiopia: prevalence, severity and associated risk factors. BMC Res Notes. 2014;7:771.

30. Ejeta E, Alemnew B, Fikadu A, Fikadu M, Tesfaye L, Birhanu T. Prevalence of anaemia in pregnant women's and associated risk factors in Western Ethiopia. Food Science and Quality Management. 2014;31:81-91.

31. Bekele A, Tilahun M, Mekuria A. Prevalence of anemia and its associated factors among pregnant women attending antenatal care in health institutions of Arba Minch town, Gamo Gofa zone, Ethiopia:a cross-sectional study. Anemia. 2016. https://doi.org/10.1155/2016/1073192.

32. Feleke $B E$, Jembere TH. Prevalence of helminthic infections and determinant factors among pregnant women in Mecha district, Northwest Ethiopia: a cross sectional study. BMC Infect Dis. 2018;18:373.

33. Derso A, Nibret E, Munshea A. Prevalence of intestinal parasitic infections and associated risk factors among pregnant women attending antenatal care center at Felege Hiwot referral hospital, Northwest Ethiopia. BMC Infect Dis. 2016;16(1):530

34. Hailu T, Abera B, Mulu W, Kassa S, Genanew A. Prevalence of intestinal parasitic infection and determinant factors among pregnant women in west Gojjam zone, Northwest Ethiopia. Accessed from: https://www. omicsonline.org/conference-proceedings/2155-9597-C2-050-022.pdf. Accessed on: 26 Nov 2018.

35. Getachew M, Yewhalaw D, Tafess K, Getachew Y, Zeynudin A. Anaemia and associated risk factors among pregnant women in Gilgel gibe dam area, Southwest Ethiopia. Parasit Vectors. 2012;5:296.

36. Jaran AS. Prevalence and seasonal variation of human intestinal parasites in patients attending hospital with abdominal symptoms in northern Jordan. East Mediterr Health J. 2017;22(10):756-60.

37. Davis EL, Danon L, Prada JM, Gunawardena SA, Truscott JE, Vlaminck J, et al. Seasonally timed treatment programs for Ascaris lumbricoides to increase impact-an investigation using mathematical models. PLoS Negl Trop Dis. 2018;12(1):e0006195

\section{Publisher's Note}

Springer Nature remains neutral with regard to jurisdictional claims in published maps and institutional affiliations.

Ready to submit your research? Choose BMC and benefit from:

- fast, convenient online submission

- thorough peer review by experienced researchers in your field

- rapid publication on acceptance

- support for research data, including large and complex data types

- gold Open Access which fosters wider collaboration and increased citations

- maximum visibility for your research: over $100 \mathrm{M}$ website views per year

At BMC, research is always in progress.

Learn more biomedcentral.com/submissions 